\section{Transpupillary thermotherapy for subfoveal leaks in central serous chorioretinopathy}

D Shukla', C Kolluru', TP Vignesh', S Karthikprakash² and R Kim ${ }^{1}$
Eye (2008) 22, 100-106; doi:10.1038/sj.eye.6702449; published online 26 May 2006

Keywords: transpupillary thermotherapy; subfoveal leak; central serous chorioretinopathy

\section{Introduction}

Central serous chorioretinopathy (CSC) is characterized by an idiopathic serous neurosensory retinal detachment at the posterior pole caused by leakage from the retinal pigment epithelium (RPE). ${ }^{1}$ There are two main types of CSC, based on the nature of RPE leak. The more common type, termed 'acute', 'typical', or 'classic' CSC, is seen in younger patients, with focal leaks from RPE, mild-moderate visual loss, and a benign self-limiting course. A second uncommon type, with widespread alterations of RPE pigmentation in the posterior pole, is termed 'chronic' or 'diffuse retinal pigment epitheliopathy' (DRPE). ${ }^{2}$ This subtype is associated with older age, chronic ( $>6$ months) detachment of the posterior pole, poorly defined RPE leakage or 'ooze,' multiple pigment epithelial detachments (PED), and poor visual prognosis owing to cystoid macular oedema, foveolar atrophy, subretinal fibrosis, and less commonly, choroidal neovascularization $(\mathrm{CNV}){ }^{2-8}$ In spite of the innumerable studies on CSC, there is continued controversy in the literature on the need, timing, and choice of treatment. The most studied treatment, conventional laser photocoagulation, is controversial in the classic CSC and unsuccessful in the chronic type. ${ }^{9-13}$ Alternative treatment modalities like photodynamic therapy (PDT) have reported anatomic, but rarely functional success, in DRPE. 5,6,14 Many recent reports on treatment and natural history
Received: 31 October 2005 Accepted in revised form: 23 April 2006 Published online: 26 May 2006
${ }^{1}$ Retina - Vitreous Service,

Correspondence: D Shukla, Postgraduate Institute of Ophthalmology,

No. 1 Anna Nagar

Tel: + 914525356100

Fax: + 914522530984 .

E-mails: daksh@aravind.org; daksh66@rediffmail.com \begin{abstract}
CSC with subfoveal angiographic leaks with significant improvement in visual outcome, in comparison to the natural history of persistent CSC.

in the resolution of the serous detachment in required a repeat treatment. Eight control follow-up. Visual acuity improved in 23 (92\%) treated and five $(33 \%)$ control eyes; the difference in outcome was statistically significant $(P<0.001)$. One case developed choroidal neovascularization, which resolved
\end{abstract}


have therefore recommended early treatment of CSC before foveal atrophy or RPE decompensation sets in. ${ }^{5,7,13-15}$

The presence of subfoveal focal leaks, which occur in less than $10 \%$ of $\mathrm{CSC}_{,}^{16}$ further confound the management dilemma. As conventional photocoagulation is not recommended for such leaks, these cases are usually observed up to 6 months, to resolve spontaneously., ${ }^{47}$ There are no clear guidelines for management if the focal leakage persists beyond 6 months. We studied the treatment outcome for persistent CSC with subfoveal RPE point leaks, where the patients opted for transpupillary thermotherapy (TTT) over observation or PDT.

\section{Materials and methods}

\section{Case selection}

The patients attending the outpatient clinic of a tertiary eye care centre with CSC and fluorescein angiographic findings of a subfoveal leak were offered the options of TTT, PDT, or observation if they fulfilled either of the following criteria:

1. CSC of at least 6 months' duration

2. CSC of less than 6 months' (but $\geq 4$ months') duration, if there were documented recurrences, bestcorrected visual acuity (BCVA) $\leq 20 / 40$, loss of vision in the fellow eye owing to chronic CSC; or if the patient's occupation required early recovery.

The patients who opted to undergo TTT were enrolled as cases. CSC with pre-existing diffuse RPE

decompensation or subretinal fibrosis, any ocular or systemic disease (like choroidal tumours / neovascularization/inflammation, or hypertension, pregnancy, etc), which could contribute to exudative detachment, or use of corticosteroids constituted the exclusion criteria. In addition, patients opting for PDT were also excluded from this study.

All the patients underwent a detailed ocular evaluation at the baseline and subsequent visits: measurement of BCVA, slit-lamp biomicroscopy, indirect ophthalmoscopy, and fundus fluorescein angiogram (FFA).

\section{Controls}

The patients who met the above criteria, but did not choose to undergo any treatment for CSC, were designated as controls. Subfoveal leak was not a mandatory criterion for controls. They were allowed treatment when desired, but were to be removed from the trial if they did.

\section{Treatment protocol}

An informed consent was obtained from all the patients. The study was approved by the Institutional Review Board. Treatment was carried out on a slit-lamp-mounted infrared diode laser (IRIS Medical, Iridex Corp. Mountain View, CA, USA), using a fundus contact lens with antireflective coating. A uniform spot size of $0.5 \mathrm{~mm}$ was used for $1 \mathrm{~min}$ in all cases, mean power used was $90 \mathrm{~mW}$ (range: $60-120 \mathrm{~mW}$ ). The power to deliver a subthreshold foveal burn was determined by test spots in the inferonasal quadrant: the end point was a minimal grey retinal discoloration. This threshold power was reduced by $10 \%$ before foveal treatment.

\section{Follow-up, outcome measures, and re-treatment}

All patients were scheduled to follow-up at 1, 3, and 6 months after the treatment. The treatment outcome was assessed in two ways: clinically/angiographically (resolution of the serous detachment and focal leak) and functionally (change in BCVA, defined as 1 or more Snellen Lines). A repeat-TTT was performed if the angiographic dye leakage persisted 3 months after the treatment. The same treatment criteria as above were followed for the re-treatment.

\section{Statistical methods}

We used Wilcoxon's signed-rank test to compare paired samples, Mann-Whitney U-test to compare independent samples, and $\chi^{2}$ test to compare the categorical variables. These analyses were performed using the statistical package STATA 8.1 (STATA Corp., College Station, TX, USA). The level of statistical significance was set at $P$-values lower than 0.05 .

\section{Results}

\section{Patient demographics}

Forty eyes of 39 patients were studied: 25 patients ( 25 eyes) were treated by TTT and 14 patients (15 eyes) served as concurrent controls. The male: female ratio was marginally higher in cases than controls $(P=0.225)$; mean age was similar among cases (41.4 years) and controls (42 years) $(P=0.758)$. The mean baseline $\log$ MAR visual acuity was also comparable in the two groups (cases, 0.495 (range: $0.17-1$ ) and controls, 0.476 (range: $0-1))(P=0.523)$. Eighteen cases and 11 controls had a fresh CSC; the remaining reported previous episodes. The average duration of CSC was significantly higher in controls than in cases (7.47 (4-12) vs 5.4 (4-9) months) $(P=0.044)$. FFA revealed a single subfoveal leak in all cases; the leak was inkblot (21) or smokestack (4). 
Three leaks arose from the edge of a PED. Four cases had previously undergone treatment for extrafoveal leaks. Twelve control eyes had a single leak; three had two leaks each: there were 15 extrafoveal and three subfoveal leaks. One control subject (eyes no. 10 and 11, Tables 1 and 2) had bilateral CSC.

\section{Treatment and follow-up of cases}

No foveal whitening was observed in any eye during/ after TTT. At 1 month, 21 cases had complete resolution of the leak and detachment (Figure 1). Three out of the four persistent detachments showed an angiographically persisting leakage. By 3 months, detachments and leaks disappeared in all but one eye, which underwent a repeat-TTT. No recurrences were seen. At 3 months, one eye developed a subfoveal $\mathrm{CNV}$, which was also treated by TTT (spot size: $2 \mathrm{~mm}$; power: $210 \mathrm{~mW}$; duration: $1 \mathrm{~min}$ ) with full visual recovery. BCVA improved in 23 (92\%) eyes, and 22 recovered to $\geq 20 / 30$ (mean final logMAR BCVA: 0.085 , range: $0-0.48)(P<0.001)$. Three eyes had a final visual acuity of 20/60: two maintained their pretreatment vision; one had improved from a pre-TTT BCVA of 20/200. Two had dense subretinal fibrin before TTT; one had had multiple recurrences (Table 1).

\section{Follow-up of controls}

The observation group maintained follow-up schedule at 1 and 3 months, but returned subsequently at varying time intervals. None underwent any treatment. The mean duration of follow-up was 10.53 months (range: 6-12 months). At the final follow-up, seven eyes (six patients) had persisting CSC (five recurrences); the remaining resolved: four without sequelae, two with focal RPE defects (Figure 2), and two with DRPE. Vision improved in five (33\%) eyes, stabilized in eight (53\%) eyes, and deteriorated in two (13\%) eyes. Six (40\%) eyes had a final BCVA of 20/30 (mean final logMAR BCVA: 0.432; range 0-1.0). Mean final BCVA (20/54) of control group did not change from the baseline value $(20 / 60)$ $(P=0.67)$, but was significantly lower than the final BCVA in treated eyes $(20 / 24)(P<0.001)$. The main causes of subnormal vision were DRPE and persisting/ recurrent CSC (Table 2).

Comparison of final visual outcome of cases and controls is depicted in Figure 3.

\section{Discussion}

We achieved anatomic and angiographic resolution of subfoveal leaks in all the cases of CSC with TTT; and in

Table 1 Cases: demographics, treatment, and follow-up

\begin{tabular}{|c|c|c|c|c|c|c|c|c|c|}
\hline S.N. & $\begin{array}{c}\text { Age } \\
\text { (years) }\end{array}$ & Sex & $\begin{array}{l}\text { Duration } \\
\text { (months) }\end{array}$ & $\begin{array}{l}\text { Previous } \\
\text { episode }\end{array}$ & $\begin{array}{l}\text { Previous } \\
\text { treatment }\end{array}$ & Pre-TTT VA & Repeat-TTT & Final $B C V A$ & $\begin{array}{c}\text { Follow-up } \\
\text { (months) }\end{array}$ \\
\hline 1 & 40 & M & 9 & + & + & $20 / 60$ & - & $20 / 20$ & 6 \\
\hline 2 & 56 & $\mathrm{~F}$ & 6 & - & - & $20 / 40$ & - & $20 / 20$ & 12 \\
\hline 3 & 52 & M & 7 & - & - & $20 / 30$ & - & $20 / 20$ & 6 \\
\hline 4 & 59 & M & 6 & + & + & $20 / 30$ & - & $20 / 20$ & 12 \\
\hline 5 & 43 & M & 4 & - & - & $20 / 200$ & - & $20 / 20$ & 6 \\
\hline 6 & 45 & $\mathrm{~F}$ & 5 & - & - & $20 / 30$ & - & $20 / 20$ & 6 \\
\hline 7 & 54 & M & 4 & + & - & $20 / 40$ & + & $20 / 20$ & 6 \\
\hline 8 & 31 & M & 6 & + & + & $20 / 60$ & - & $20 / 20$ & $6^{\mathrm{a}}$ \\
\hline 9 & 54 & M & 4 & - & - & $20 / 60$ & - & $20 / 60$ & 6 \\
\hline 10 & 33 & M & 6 & - & - & $20 / 40$ & - & $20 / 20$ & 6 \\
\hline 11 & 35 & M & 4 & - & - & $20 / 80$ & - & $20 / 20$ & 6 \\
\hline 12 & 37 & M & 4 & - & - & $20 / 60$ & - & $20 / 30$ & 6 \\
\hline 13 & 39 & M & 7 & - & - & $20 / 40$ & - & $20 / 20$ & 6 \\
\hline 14 & 43 & M & 4 & + & - & $20 / 60$ & - & $20 / 30$ & 6 \\
\hline 15 & 42 & $\mathrm{M}$ & 4 & - & - & $20 / 200$ & - & $20 / 60$ & 6 \\
\hline 16 & 31 & $\mathrm{~F}$ & 5 & - & - & $20 / 80$ & - & $20 / 20$ & 6 \\
\hline 17 & 46 & M & 4 & + & - & $20 / 120$ & - & $20 / 20$ & 6 \\
\hline 18 & 47 & $\mathrm{M}$ & 5 & - & - & $20 / 60$ & - & $20 / 20$ & 6 \\
\hline 19 & 39 & M & 7 & - & - & $20 / 40$ & - & $20 / 30$ & 6 \\
\hline 20 & 42 & M & 8 & + & - & $20 / 40$ & - & $20 / 20$ & 6 \\
\hline 21 & 30 & M & 4 & - & - & $20 / 120$ & - & $20 / 20$ & 6 \\
\hline 22 & 27 & M & 4 & - & - & $20 / 200$ & - & $20 / 20$ & 6 \\
\hline 23 & 47 & M & 6 & - & - & $20 / 60$ & - & $20 / 20$ & 6 \\
\hline 24 & 35 & M & 7 & - & - & $20 / 60$ & - & $20 / 30$ & 6 \\
\hline 25 & 38 & $\mathrm{M}$ & 5 & + & + & $20 / 60$ & - & $20 / 60$ & 6 \\
\hline
\end{tabular}

BCVA, best-corrected visual acuity; TTT, transpupillary thermotherapy; M, male; F, female; VA, visual activity.

${ }^{a}$ This patient developed a subfoveal CNV which was treated again by TTT. 
Table 2 Controls: demographics, recurrences, and follow-up

\begin{tabular}{rcccccccc}
\hline S.N & Age (years) & Sex & Duration & Baseline BCVA & Final BCVA & Follow-up & Recurrences & Final CSC status \\
\hline 1 & 40 & M & 4 & $20 / 200$ & $20 / 200$ & 12 & 0 & DRPE \\
2 & 42 & F & 12 & $20 / 20$ & $20 / 20$ & 12 & 3 & Persisting \\
3 & 28 & M & 4 & $20 / 200$ & $20 / 200$ & 6 & 0 & Resolved \\
4 & 42 & M & 12 & $20 / 200$ & $20 / 60$ & 12 & 1 & Resolved \\
5 & 41 & F & 9 & $20 / 60$ & $20 / 200$ & 12 & 0 & Persisting \\
6 & 47 & M & 6 & $20 / 200$ & $20 / 120$ & 6 & 0 & Resolved \\
7 & 40 & M & 12 & $20 / 20$ & $20 / 20$ & 12 & 0 & Resolved \\
8 & 32 & F & 5 & $20 / 40$ & $20 / 20$ & 12 & 0 & Resolved \\
9 & 46 & M & 6 & $20 / 30$ & $20 / 30$ & 9 & 1 & Persisting \\
10 & 42 & M & 6 & $20 / 40$ & $20 / 20$ & 12 & 0 & Resolved \\
11 & 42 & M & 6 & $20 / 20$ & $20 / 60$ & 12 & 2 & Persisting \\
12 & 42 & M & 8 & $20 / 80$ & $20 / 40$ & 8 & 1 & Persisting \\
13 & 35 & F & 12 & $20 / 40$ & $20 / 40$ & 12 & 0 & Persisting \\
14 & 45 & M & 6 & $20 / 20$ & $20 / 20$ & 12 & 2 & Persisting \\
15 & 65 & M & 4 & $20 / 200$ & $20 / 200$ & 9 & 0 & DRPE
\end{tabular}

BCVA, best-corrected visual acuity; CSC, central serous chorioretinopathy; DRPE, diffuse retinal pigment epitheliopathy; M, male; F, female.
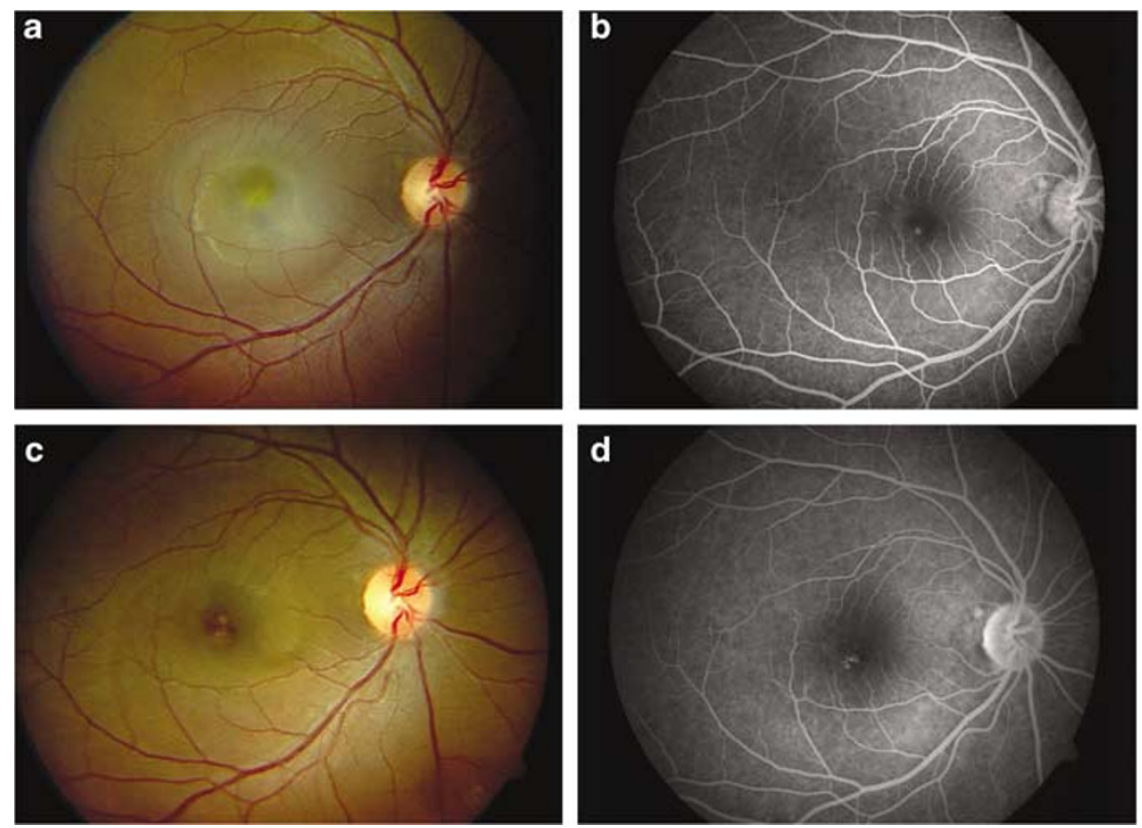

Figure 1 (a) Fundus photograph of this 30-year-old man (case no. 21) shows a serous macular detachment, consistent with CSC, with a few subretinal precipitates temporally. (b) FFA shows a focal leak within the FAZ. (c) A month after TTT, the CSC has resolved completely, with RPE defects in the foveal centre. (d) Late-phase FFA confirms the resolution of foveal leak.

$92 \%$, with a single intervention. The visual as well as anatomic outcome was significantly better than in control group. The only complication of the study was development of a subfoveal CNV, which was also successfully treated with TTT.

There are reports in the literature of treatment of subfoveal/juxtafoveal leakage in CSC. Slusher ${ }^{18}$ reported the safety and efficacy of krypton-red laser photocoagulation in CSC within $100 \mu \mathrm{m}$ of the edge of foveal avascular zone (FAZ). Yannuzzi et al ${ }^{19}$ used grid-pattern krypton-red laser inside the FAZ also, for chronic DRPE in CSC. Recently, they employed PDT for such cases. However, like red laser, PDT also failed to improve the visual outcome, as reported by others as well., ${ }^{5}$ Canakis et al and later Taban et al have reported improved visual outcome after PDT for chronic CSC, which they correlated with preoperative visual acuity, and recommended early treatment for better results, ${ }^{14,20}$ endorsed by others. $5,8,13,15$ 

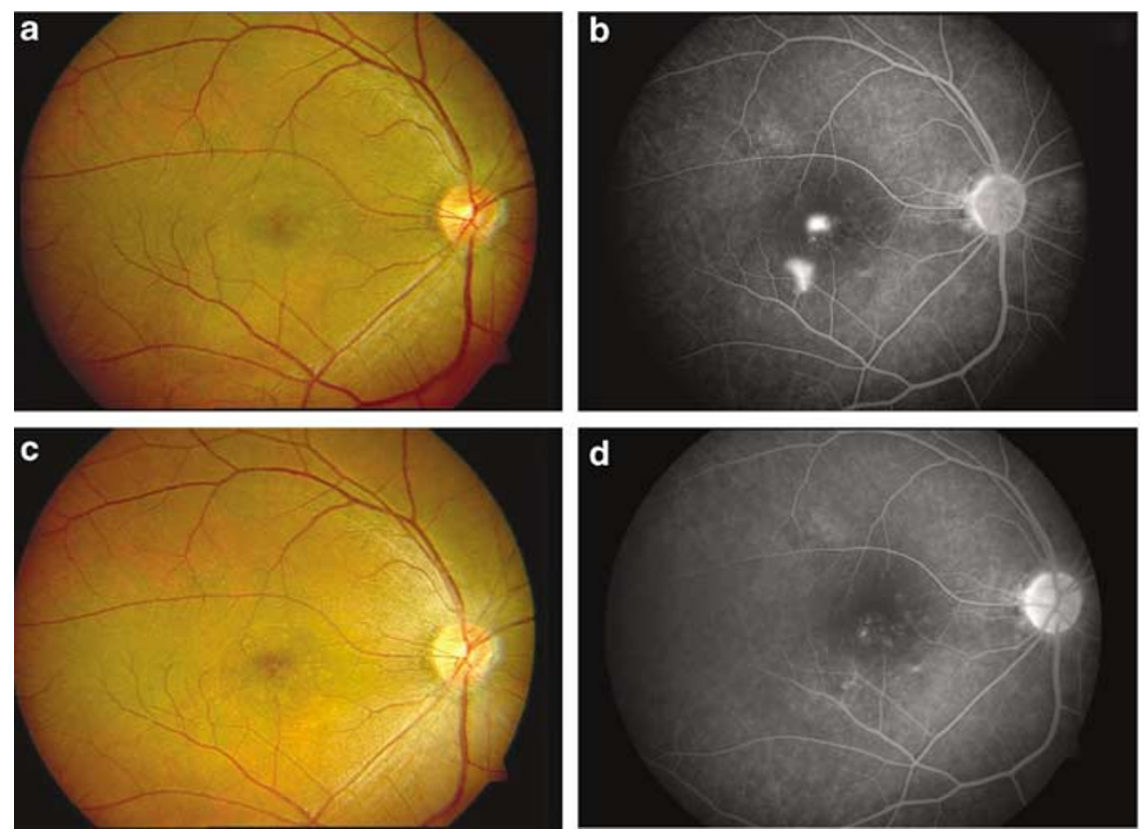

Figure 2 (a) This 47-year-old man (control no. 6) had CSC persisting for 6 months in the right eye. Note the subretinal precipitates and RPE defects. (b) FFA showed a subfoveal inkblot leak, and an extrafoveal smokestack. Faint hyperfluorescence of RPE defects was also evident. (c) The CSC resolved spontaneously over 6 months with more precipitates and RPE mottling; vision improved marginally (20/200-20/120). (d) Angiogram confirmed the absence of leakage, and showed RPE window defects in and around fovea.

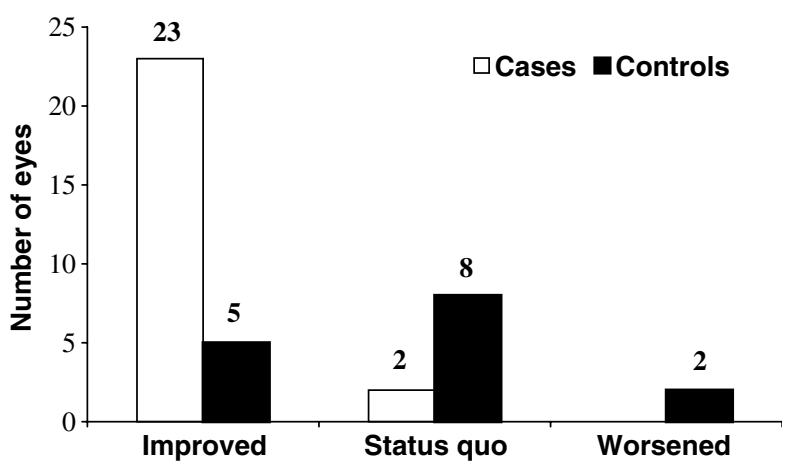

Figure 3 Bar chart comparing the visual outcome of cases and controls. Improvement/worsening of BCVA was defined as a change of 1 or more Snellen lines.

There is no consensus on how early the 'early' treatment should be applied: foveal atrophy may occur anytime after 4 months of foveal detachment, ${ }^{15}$ chronic degenerative changes in macula are likely after 6 months; ${ }^{5}$ both result in a poor visual outcome. We selected cases where the subfoveal RPE leak was still focal in character despite persistent foveal detachment, before chronic changes were likely to set in. Owing to focal nature of the leaks, we did not need ICG to look for hyperpermeable areas. Interestingly, two reports that showed significant visual improvement with PDT in chronic CSC also used FFA rather than ICG, ${ }^{14,20}$ considered essential by others. ${ }^{2,5,6}$

TTT has been successfully used to treat subfoveal CNV of various aetiologies. ${ }^{21-23}$ Owing to its thermal nature, TTT may act like conventional photocoagulation in CSC, causing RPE debridement, migration, transformation, and re-proliferation. ${ }^{14,24}$ TTT raises the temperature at the level of RPE and choroid by approximately $10^{\circ} \mathrm{C}$ (1/4-1/6 of the hyperthermia caused by conventional photocoagulation). Its deep, low, and prolonged hyperthermia induces hyper-expression of heat-shock proteins, apoptosis of endothelial cells, and vascular thrombosis, mainly in the choroid. ${ }^{24,25}$ As choriocapillaris hyperpermeability and leakage is the uniformly observed pathology in $\mathrm{CSC}^{3}$ choriocapillaris closure by TTT may result in a blood flow stasis and decreased leakage, similar to the mechanism attributed to PDT in CSC. ${ }^{3,5,14}$ Others concur that there is similarity of pathophysiological response between TTT and PDT. ${ }^{26}$ At the same time, human/animal studies report minimal/reversible damage to the overlying neural retina with low-medium dose TTT, in the absence of clinically visible retinal blanching. ${ }^{26-28}$ However, the therapeutic window of TTT is probably narrow. ${ }^{26}$ An animal study showed that even clinically subthreshold TTT could damage the neural retina. ${ }^{29}$ Indeed, macular burn and visual loss has been reported after TTT for CNV. ${ }^{30}$ However, in CSC, subretinal fluid probably 
protects the retina from thermal damage. ${ }^{26,27,29}$ Further, subretinal pigmented lesions or blood, which accentuate neural retinal damage,,$^{27,28}$ are absent in CSC. Therefore, it is possible that TTT may be relatively safer in CSC as compared to other exudative submacular pathologies. None of the treated patients in our study lost any vision. In fact, all eyes with baseline acuity of $\geq 20 / 40$ improved by $\geq 1$ Snellen lines.

Our natural history group, which failed to improve from its baseline status, behaved differently from some studies, where visual recovery was excellent and independent of intervention. We attribute this discrepancy to the fact that many studies either did not report the duration of CSC at baseline or selected patients for treatment/observation without waiting for 4-6 months. ${ }^{9-11}$ Therefore, the favourable natural history attributed to acute CSC, irrespective of photocoagulation, might not be applicable to persistent CSC. Burumcek et al selected only subjects with CSC for 4 months in their prospective study. They reported, like us, significant benefit from intervention in 'persistent' CSC compared to controls, where $50 \%$ detachments persisted, and mean final BCVA failed to improve, similar to our study. ${ }^{13}$

This study had some limitations. The groups were small and not uniform in size, they were not randomized, and the follow-up was relatively short. Therefore, we cannot comment on the long-term safety of TTT and stability of study outcomes. As we did not use OCT in our study, we were unable to correlate the poor visual outcome with pathoanatomical variables like foveal atrophy and cystoid macular degeneration. ${ }^{7,15}$ Further, the mean baseline duration of CSC was slightly longer in controls (7.5 vs 5.4 months), which could have affected their outcome. A larger and long-term randomized trial is required to address the above unsolved issues in this pilot trial. We had a $4 \%$ incidence of $\mathrm{CNV}$, which is comparable to $4-8 \%$ incidence in the natural history of CSC. ${ }^{11,31}$ Others have reported similar complication after PDT in a smaller case series. ${ }^{32}$

Although acute CSC has a favourable natural course, chronic persistence spells risk of poor visual outcome, perhaps to a greater extent in our ethnic background. Some authors have suggested a racial predisposition of CSC: it appears to be more common as well as more severe in Asians, Hispanics, and Latinos than in Caucasians; blacks appear to be least affected. ${ }^{4,17}$ The chronic and severe variants have been reported more frequently from the Asian countries than from the West. ${ }^{33,34}$ We propose TTT as an effective and safe alternative to PDT for subfoveal treatment of persistent CSC with focal leaks. Adequate care should be exercised in applying this treatment in a subthreshold manner, to avoid complications like CNV and macular burn.

\section{References}

1 Gass JDM. Pathogenesis of disciform detachment of the neuroepithelium: II. Idiopathic central serous chorioretinopathy. Am J Ophthalmol 1967; 63: 587-615.

2 Spaide RF, Campeas L, Haas A, Yannuzzi LA, Fisher YL, Guyer DR et al. Central serous retinopathy in younger and older adults. Ophthalmology 1996; 103: 2070-2080.

3 Spaide RF, Goldbaum M, Wong DW, Tang KC, Iida T. Serous detachment of the retina. Retina 2003; 23: 820-846.

4 Gass JDM. Stereoscopic Atlas Of Macular Diseases: Diagnosis And Treatment, 4th ed., Vol. 1. Mosby: St Louis, MO, 1997, pp 52-70.

5 Yannuzzi LA, Slakter JS, Gross NE, Spaide RF, Costa DL, Huang SJ et al. Indocyanine green angiography guided photodynamic therapy for chronic central serous chorioretinopathy. Retina 2003; 23: 288-298.

6 Cardillo Piccolino F, Eandi CM, Ventre L, Rigault de la Longrais RC, Grignolo FM. Photodynamic therapy for chronic central serous retinopathy. Retina 2003; 23: 752-763.

7 Iida T, Yannuzzi LA, Spaide RF, Borodoker N, Carvalho CA, Negrao S. Cystoid macular degeneration in chronic central serous chorioretinopathy. Retina 2003; 23: 1-7.

8 Levine R, Brucker AJ, Robinson F. Long term follow-up of idiopathic central serous chorioretinopathy by flourescein angiography. Ophthalmology 1989; 96: 854-859.

9 Ficker L, Vafidis G, While A, Leaver P. Long-term follow-up of a prospective trial of argon laser photocoagulation in the treatment of central serous retinopathy. $\mathrm{Br} J$ Ophthalmol 1988; 72: 829-834.

10 Gilbert CM, Owens SL, Smith PD, Fine SL. Long-term follow-up of central serous chorioretinopathy. $\mathrm{Br} J$ Ophthalmol 1984; 68: 815-820.

11 Loo RH, Scott IU, Flynn Jr HW, Gass JD, Murray TG, Lewis ML et al. Factors associated with reduced visual acuity during long-term follow-up of patients with idiopathic central serous chorioretinopathy. Retina 2002; 22: 19-24.

12 Eng-Yiat Y, Robertson DM. The long term outcome of central serous chorioretinopathy. Arch Ophthalmol 1996; 114: 689-692.

13 Burumcek E, Mudun A, Karacorlu S, Arslan MO. Laser photocoagulation for persistent central serous retinopathy: results of long-term follow-up. Ophthalmology 1997; 104: 616-622.

14 Taban M, Boyer DS, Thomas EL, Taban M. Chronic central serous chorioretinopathy: photodynamic therapy. Am J Ophthalmol 2004; 137: 1073-1080.

15 Wang MS, Sander B, Larsen M. Retinal atrophy in idiopathic central serous chorioretinopathy. Am J Ophthalmol 2002; 133: 787-793.

16 Spitznas M, Huke J. Number, shape and topography of leakage points in acute type I central serous retinopathy. Graefes Arch Clin Exp Ophthalmol 1987; 225: 437-440.

17 Ciardella AP, Guyer DR, Spitznas M, Yannuzzi LA. Central serous chorioretinopathy. In: Ryan SJ (ed). Retina, 3rd ed., Vol. 2. Mosby: St Louis, MO, 2001, pp 1153-1181.

18 Slusher MM. Krypton red laser photocoagulation in selected cases of central serous chorioretinopathy. Retina 1986; 6 : 81-84.

19 Yannuzzi LA, Slakter JS, Kaufman SR, Gupta K. Laser treatment of diffuse retinal pigment epitheliopathy. Eur J Ophthalmol 1992; 2: 103-114.

20 Canakis C, Livir-Rallatos C, Panayiotis Z, Livir-Rallatos G, Persidis E, Conway MD et al. Ocular photodynamic therapy 
for serous macular detachment in the diffuse retinal pigment epitheliopathy variant of idiopathic central serous chorioretinopathy. Am J Ophthalmol 2003; 136: 750-752.

21 Newsom RS, McAlister JC, Saeed M, El-Ghonemy K, McHugh JD. Results 28 months following transpupillary thermotherapy for classic and occult choroidal neovascularization in patients with age-related macular degeneration. Ophthalmic Surg Lasers Imag 2005; 36: 94-102.

22 Kumar A, Prakash G, Singh RP. Transpupillary thermotherapy for idiopathic subfoveal choroidal neovascularization. Acta Ophthalmol Scand 2004; 82: 205-208.

23 Shukla D, Singh J, Kolluru CM, Kim R, Namperumalsamy P. Transpupillary thermotherapy for subfoveal neovascularization secondary to group 2A idiopathic juxtafoveolar telangiectasis. Am J Ophthalmol 2004; 138: 147-149.

24 Mainster MA, Reichel E. Transpupillary thermotherapy for age related macular degeneration: long-pulse photocoagulation, apoptosis, and heat shock proteins. Ophthalmic Surg Lasers 2000; 31: 359-373.

25 Desmettre T, Maurage CA, Mordon S. Heat shock protein hyperexpression on chorioretinal layers after transpupillary thermotherapy. Invest Ophthalmol Vis Sci 2001; 42: 2976-2980.

26 Ming Y, Algvere PV, Odergren A, Berglin L, van der Ploeg I Seregard $S$ et al. Subthreshold transpupillary thermotherapy reduces experimental choroidal neovascularization in the mouse without collateral damage to the neural retina. Invest Ophthalmol Vis Sci 2004; 45: 1969-1974.

27 Robertson DM, Salomao DR. The effect of transpupillary thermotherapy on the human macula. Arch Ophthalmol 2002; 120: $652-656$.
28 Connolly BP, Regillo CD, Eagle Jr RC, Shields CL, Shields JA, Moran H. The histopathologic effects of transpupillary thermotherapy in human eyes. Ophthalmology 2003; 110: 415-420.

29 Morimura Y, Okada AA, Hayashi A, Fujioka S, Hashida N, Kawahara $\mathrm{S}$ et al. Histological effect and protein expression in subthreshold transpupillary thermotherapy in rabbit eyes. Arch Ophthalmol 2004; 122 1510-1515.

30 Benhamou N, Cohen SY, Erginay A, Uzzan J, Brasseur G, Avni I et al. Macular burn after transpupillary thermotherapy for occult choroidal neovascularization. Am J Ophthalmol 2004; 137: 1132-1135.

31 Bandello F, Virgili G, Lanzetta P, Pirracchio A, Menchini U. ICG angiography and retinal pigment epithelial decompensation (CRSC and epitheliopathy). J Fr Ophthalmol 2001; 24: 448-451.

32 Chan WM, Lam DS, Lai TY, Tam BS, Liu DT, Chan CK. Choroidal vascular remodelling in central serous chorioretinopathy after indocyanine green guided photodynamic therapy with verteporfin: a novel treatment at the primary disease level. $\mathrm{Br} J$ Ophthalmol 2003; 87: 1453-1458.

33 Sharma T, Badrinath SS, Gopal L, Ravishankar K, Shanmugam MP, Bhende $\mathrm{P}$ et al. Subretinal fibrosis and nonrhegmatogenous retinal detachment associated with multifocal central serous chorioretinopathy. Retina 1998; 18: 23-29.

34 Otsuka S, Ohba N, Nakao K. A long-term follow-up study of severe variant of central serous chorioretinopathy. Retina 2002; 22: 25-32. 